\title{
Mathematical Modelling and Simulation of Combined Trajectory Paths of a Seven Link Biped Robot
}

\author{
Ahmad Bagheri, Behnam Miripour-Fard and Peiman Naseradin Mousavi \\ The University of Guilan, Faculty of Engineering \\ Iran
}

\section{Introduction}

The humanoid robot is designed like human for doing various tasks and adapting to human's environment. Next generation humanoids are expected to successfully coexist within human environments. This imposes very difficult challenges to researchers to produce truly dynamic movements to maintain balance under unexpected changes of paths. There are vast majority of studies on single trajectory paths of the biped robot (Bagheri \& Mousavi, 2007; Mousavi \& Bagheri, 2007) while combined trajectory paths have not received much attention. In this chapter, we have hence focused on generation of combined trajectory paths with the aid of mathematical interpolation. Zarrugh and Radcliffe (1997) have considered a biped robot with respect to a walking pattern by recording human kinematic data while McGeer (1990) have focused on passive walking of a biped robot generated by gravitational and inertial components. Silva and Machado (1999) have focused on actuator power and energy by the adaptation of walking parameters. The stability of the robot is connected to the biped robot's tendency to tip over. Zheng and Shen (1990) have considered a method of gait synthesis with respect to static stability while Chevallereau (1998) have focused on dynamic stability with the aid of a low energy reference trajectory definition. Takanishi et al. (1985), Shih et al. (1990), Hirai et al. (1998), and Dasgupta and Nakamura (1999) have considered the robot dynamic stability with respect to the walking process based on the zero moment point (ZMP) method. With respect to the various conditions of combined trajectory paths, Shih $(1997,1999)$, Huang et al. (2001) utilized methods to generate the trajectory paths of the robot where they carried out simulation of the combined trajectory paths.

The current chapter focuses on the inverse kinematic and dynamic methods for providing the robot combined trajectory paths in order to obtain a smooth motion of the robot. This procedure avoids the link's velocity discontinuities of the robot in order to mitigate the occurrence of impact effects and also helps to obtain a suitable control process. The main contribution of this work consists of a new method for simulation of a seven link biped robot over combined trajectory paths in order to study the effects of hip height over the torso's modified motion. The process has been performed based on the system given breakpoints and either third-order spline or Vandermonde matrix interpolation method. 
The employed methods generate the desired combined trajectory paths to avoid oscillation of the paths because of the high order of the polynomials. The simulations have been carried out for combined trajectory paths. Similar to human gait, the robot's feet make negative, zero and positive angles with the ground.

\section{Kinematic modelling}

The mathematical interpolation is one of the simplest methods utilized for obtaining the suitable curves with respect to the given break points that the robot must undergo. The process of inverse kinematics with the aid of the defined combined trajectory paths (they have been indicated by the operator) and also solving the nonlinear equations for the robot movement will result in the needed parameters. Parameters such as joint angles will be calculated for use in dynamics and the subsequent controlling equations before the actual calculation of the actuator torques. The actuator torques will be used in the indicated combined trajectory paths. In the current chapter, the simplest mathematical interpolations which are "Vandermonde matrix" and "third-order spline" (Mousavi \& Bagheri, 2007; Huang et al., 2001) have been used. The mathematical equations of a biped robot are nonlinear systems of equations which contain complex mathematical relations. In Figs. 1 and 2, the robot sagittal schematic has been presented to indicate the required nodes and the utility of the mentioned curves. With utilization of the specified criteria, the generated paths will be exploited in the designed software to obtain the kinematic parameters.

In general and with respect to Fig. 1, all the needed and important robot parameters are listed as follows:

(a) Hip parameters: The hip parameters include the vertical and horizontal displacements of the joint $\left(z_{h}, x_{h}\right)$ and the variables which are displayed by Figs. 1 and 2, respectively. The distance between the hip and the fixed coordinate system (which is on the support leg) will be denoted for the instants of the beginning and the end points of the double support phase by $\mathrm{x}_{\mathrm{ed}}, \mathrm{x}_{\mathrm{sd}}$, respectively (Huang et al., 2001).

(b) Foot parameters: During the walking cycle, the horizontal and vertical displacements of ankle joint are displayed by $\mathrm{x}_{\mathrm{a}}, \mathrm{z}_{\mathrm{a}}$, respectively. The other parameters are as follows:

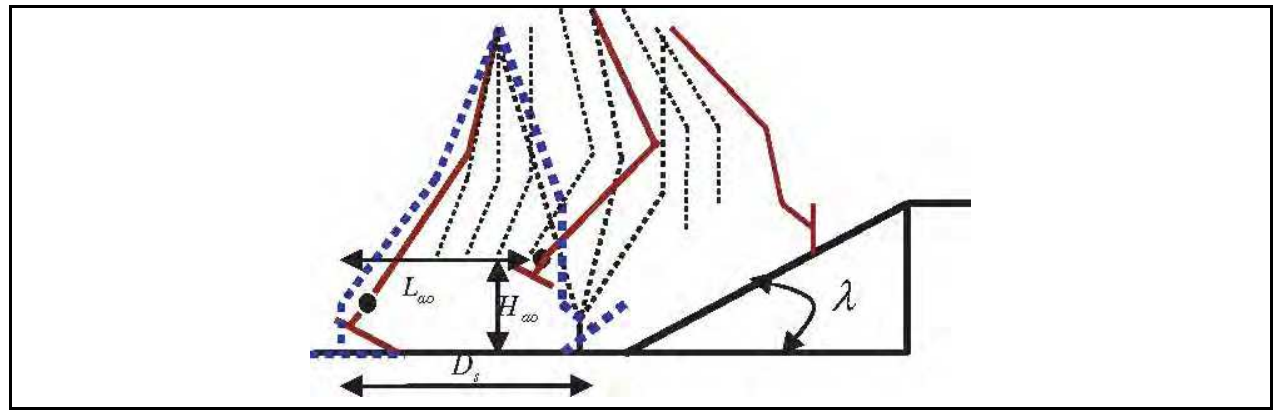

Fig. 1. The robot variables. 


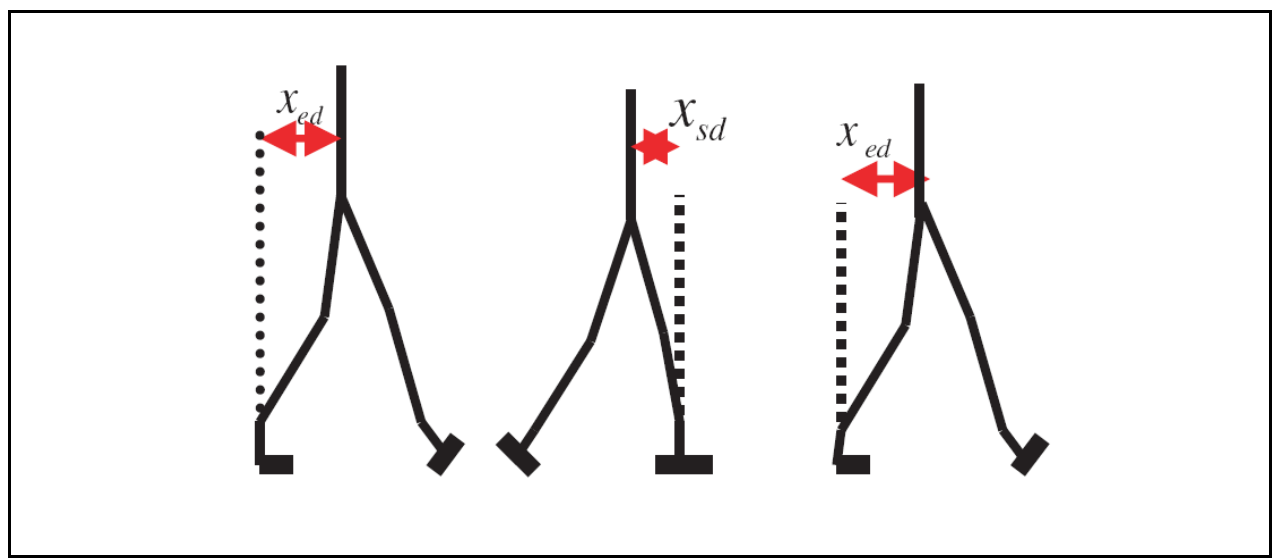

Fig. 2. The hip variables: $x_{\text {ed }}, x_{\text {sd }}$.

$T_{c} \quad$ total traveling time including single and double support phases

$T_{d} \quad$ double support phase time which is regarded as $\approx 20 \%$ of $T_{c}$

$T_{m} \quad$ the time at which the ankle joint has reached the maximum height during the walking cycle

$k \quad$ step number

$H_{a o} \quad$ ankle joint maximum height

$L_{a o} \quad$ the horizontal distance traveled between the ankle joint and the start point when the ankle joint has reached its maximum height

$D_{s} \quad$ step length

$q_{b}, q_{f} \quad$ foot lift angle and contact angle with the level ground

$q_{g s}, q_{g f} \quad$ the ground initial terrain angles

$h_{s t} \quad$ stair level height

$H_{s t} \quad$ foot maximum height from stair level.

\subsection{Foot trajectory interpolation}

Five phases are required for calculation of the foot's combined trajectory path as shown in Fig. 3; they are derived as follow:

-First and fifth phases:

$$
\theta_{a}(t)= \begin{cases}-q_{g s} & t=k T_{c} \\ -q_{b} & t=k T_{c}+T_{d} \\ q_{f} & t=(k+1) T_{c} \\ q_{g f} & t=(k+1) T_{c}+T_{d}\end{cases}
$$

-Second phase: 


$$
\theta_{a}(t)= \begin{cases}-q_{g s} & t=k T_{c} \\ -q_{b} & t=k T_{c}+T_{d} \\ q_{f}+\lambda & t=(k+1) T_{c} \\ q_{g f}+\lambda & t=(k+1) T_{c}+T_{d}\end{cases}
$$

-Third phase:

$$
\theta_{a}(t)= \begin{cases}-q_{g s}+\lambda & t=k T_{c} \\ -q_{b}+\lambda & t=k T_{c}+T_{d} \\ q_{f}+\lambda & t=(k+1) T_{c} \\ q_{g f}+\lambda & t=(k+1) T_{c}+T_{d}\end{cases}
$$

-Fourth phase:

$$
\theta_{a}(t)= \begin{cases}-q_{g s}+\lambda & t=k T_{c} \\ -q_{b}+\lambda & t=k T_{c}+T_{d} \\ q_{f} & t=(k+1) T_{c} \\ q_{g f} & t=(k+1) T_{c}+T_{d}\end{cases}
$$

In the current process of the polynomial determination, boundary conditions of the movement play an important role for calculation of the combined trajectory paths. The required boundary conditions are derived with respect to the system requirements. Similar to the human walking process, foot angular velocity $\left(\dot{\theta}_{a}\right)$ at the specified moments including the instants of the beginning and the end of foot traveling is equal to zero:

$$
\dot{\theta}_{a}\left[t=k T_{c}, t=k T_{c}+T_{d}\right]=0
$$

With respect to relations (1)-(4), a third-order spline can be utilized to provide the foot trajectory for the combined trajectory paths. Similar processes are exploited to calculate the trajectory paths for the displacements of horizontal and vertical foot traveling as shown below.

The displacement of the horizontal coordinates of the foot for the calculated breakpoints can be obtained as follows:

-First phase (Mousavi, 2006):

$$
x_{\text {a level ground }}(t)= \begin{cases}k D_{s} & t=k T_{c} \\ k D_{s}+l_{a n} \sin q_{b}+l_{a f}\left(1-\cos q_{b}\right) & t=k T_{c}+T_{d} \\ k D_{s}+L_{a o} & t=k T_{c}+T_{m} \\ (k+2) D_{s}-l_{a n} \sin q_{f}-l_{a b}\left(1-\cos q_{f}\right) & t=(k+1) T_{c} \\ (k+2) D_{s} & t=(k+1) T_{c}+T_{d}\end{cases}
$$

-Second phase: 


$$
x_{\text {a transient } 11}(t)= \begin{cases}k_{c h} D_{s} & t=k T_{c} \\ k_{c h} D_{s}+l_{a n} \sin q_{b}+l_{a f}\left(1-\cos q_{b}\right) & t=k T_{c}+T_{d} \\ k_{c h} D_{s}+L_{a o} & t=k T_{c}+T_{m} \\ \left(k_{c h}+2\right) D_{s}+\left(D_{s}-l_{a b}\right) \cos \lambda-\cdots & t=(k+1) T_{c} \\ l_{a n} \sin \left(q_{f}+\lambda\right)+l_{a b} \cos \left(q_{f}+\lambda\right) & \\ \left(k_{c h}+1\right) D_{s}+D_{s} \cos \lambda-l_{a n} \sin q_{f} & t=(k+1) T_{c}+T_{d}\end{cases}
$$

-Third phase:

$$
x_{\text {a transient } 1}(t)= \begin{cases}\left(k_{c h}+1\right) D_{s} & t=k T_{c} \\ \left(k_{c h}+1\right) D_{s}+l_{a n} \sin q_{b}+l_{a f}\left(1-\cos q_{b}\right) & t=k T_{c}+T_{d} \\ \left(k_{c h}+1\right) D_{s}+L_{a o} \cos \lambda & t=k T_{c}+T_{m} \\ \left(k_{c h}+1\right) D_{s}+\left(2 D_{s}-l_{a b}\right) \cos \lambda-\cdots & t=(k+1) T_{c} \\ l_{a n} \sin \left(q_{f}+\lambda\right)+l_{a b} \cos \left(q_{f}+\lambda\right) & \\ \left(k_{c h}+1\right) D_{s}+2 D_{s} \cos \lambda-l_{a n} \sin q_{f} & t=(k+1) T_{c}+T_{d}\end{cases}
$$

-Fourth phase:

$$
x_{a D e c}(t)=\left\{\begin{array}{lc}
\left(k_{c h}+1\right) D_{s}+D e c_{s t} D_{s} \cos \lambda-l_{a n} \sin \lambda & t=k T_{c} \\
\left(k_{c h}+1\right) D_{s s}+\left(D e c_{s t} D_{s}+l_{a f}\right) \cos \lambda-\cdots & t=k T_{c}+T_{d} \\
l_{a f} \cos \left(q_{b}-\lambda\right)+l_{a n} \cos \left(q_{b}-\lambda\right) & \\
\left(k_{c h}+1\right) D_{s}+\left(D e c_{s s}+L_{a o}\right) \cos \lambda & t=k T_{c}+T_{m} \\
\left(k_{c h}+1\right) D_{s}+\left(\left(D e c_{s t}+2\right) D_{s}-l_{a b}\right) \cos \lambda-\cdots & t=(k+1) T_{c} \\
l_{a n} \sin \left(q_{f}+\lambda\right)+l_{a b} \cos \left(q_{f}+\lambda\right) & \\
\left(k_{c h}+1\right) D_{s}+\left(D e c_{s t}+2\right) D_{s} \cos \lambda-l_{a n} \sin q_{f} & t=(k+1) T_{c}+T_{d}
\end{array}\right.
$$

-Fifth phase:

$$
x_{a, \text { tran } 2}(t)=\left\{\begin{array}{lc}
\left(k_{c h}+1\right) D_{s}+\left(D e c_{s t}+1\right) D_{s} \cos \lambda-l_{a n} \sin \lambda & t=k T_{c} \\
\left(k_{c h}+1\right) D_{s s}+\left(\left(D e c_{s t}+1\right) D_{s}+l_{a f}\right) \cos \lambda-\cdots & t=k T_{c}+T_{d} \\
l_{a f} \cos \left(q_{b}-\lambda\right)+l_{a n} \cos \left(q_{b}-\lambda\right) & \\
\left(k_{c h}+1\right) D_{s}+\left(\left(D e c_{s s}+1\right) D_{s}+L_{a o}\right) \cos \lambda & t=k T_{c}+T_{m} \\
\left(k_{c h}+1\right) D_{s}+\left(\left(k_{c h 2}-k_{c h 1}\right) D_{s}\right) \cos \lambda+D_{s}+\cdots & t=(k+1) T_{c} \\
l_{a b} \cos \left(q_{f}-1\right)-l_{a n} \sin q_{f} & \\
\left(k_{c h}+1\right) D_{s}+\left(k_{c h 2}-k_{c h 1}\right) D_{s} \cos \lambda+D_{s} & t=(k+1) T_{c}+T_{d}
\end{array}\right.
$$

-Six phase: 


$$
x_{a, t r a n 2}(t)=\left\{\begin{array}{lc}
\left(k_{c h}+1\right) D_{s}+\left(D e c_{s t}+2\right) D_{s} \cos \lambda-l_{a n} \sin \lambda & t=k T_{c} \\
\left(k_{c h}+1\right) D_{s s}+\left(\left(D e c_{s t}+2\right) D_{s}+l_{a f}\right) \cos \lambda-\cdots & t=k T_{c}+T_{d} \\
l_{a f} \cos \left(q_{b}-\lambda\right)+l_{a n} \cos \left(q_{b}-\lambda\right) & \\
\left(k_{c h}+1\right) D_{s}+\left(\left(k_{c h 2}-k_{c h 1}\right) D_{s}\right) \cos \lambda+L_{a o} & t=k T_{c}+T_{m} \\
\left(k_{c h}+1\right) D_{s}+\left(\left(k_{c h 2}-k_{c h 1}\right) D_{s}\right) \cos \lambda+2 D_{s}+\cdots & t=(k+1) T_{c} \\
l_{a b} \cos \left(q_{f}-1\right)-l_{a n} \sin q_{f} & \\
\left(k_{c h}+1\right) D_{s}+\left(k_{c h 2}-k_{c h 1}\right) D_{s} \cos \lambda+2 D_{s} & t=(k+1) T_{c}+T_{d}
\end{array}\right.
$$

-Seven phase:

$$
x_{a, \text { level ground }}(t)=\left\{\begin{array}{lc}
\left(k_{c h}+1\right) D_{s}+\left(\left(k_{c h 2}-k_{c h 1}\right) D_{s}\right) \cos \lambda+\operatorname{Lev}_{s t} D_{s} & t=k T_{c} \\
\left(k_{c h}+1\right) D_{s s}+\left(\left(k_{c h 2}-k_{c h 1}\right) D_{s}\right) \cos \lambda+\operatorname{Lev}_{s t} D_{s}-\cdots & t=k T_{c}+T_{d} \\
l_{a f}\left(1-\cos q_{b}\right)+l_{a n} \cos q_{b} & \\
\left(k_{c h}+1\right) D_{s}+\left(\left(k_{c h 2}-k_{c h 1}\right) D_{s}\right) \cos \lambda+L e v_{s t} D_{s}+L_{a o} & t=k T_{c}+T_{m} \\
\left(k_{c h}+1\right) D_{s}+\left(\left(k_{c h 2}-k_{c h 1}\right) D_{s}\right) \cos \lambda+\cdots & t=(k+1) T_{c} \\
\left(L e v_{s t}+2\right) D_{s}+l_{a b} \cos \left(q_{f}-1\right)-l_{a n} \sin q_{f} & \\
\left(k_{c h}+1\right) D_{s}+\left(k_{c h 2}-k_{c h 1}\right) D_{s} \cos \lambda+\left(L e v_{s t}+2\right) D_{s} & t=(k+1) T_{c}+T_{d}
\end{array}\right.
$$

The displacement of the vertical coordinates of the foot for the calculated breakpoints can be obtained as follows:

-First phase (Mousavi, 2006):

$$
z_{a, \text { level ground }}(t)= \begin{cases}h_{g s}+l_{a n} & t=k T_{c} \\ h_{g s}+l_{a f} \sin q_{b}+l_{a n} \cos q_{b} & t=k T_{c}+T_{d} \\ H_{a o} & t=k T_{c}+T_{m} \\ h_{g e}+l_{a b} \sin q_{f}+l_{a n} \cos q_{f} & t=(k+1) T_{c} \\ h_{g e}+l_{a n} & t=(k+1) T_{c}+T_{d}\end{cases}
$$

-Second phase:

$$
z_{a, \text { transient }}(t)=\left\{\begin{array}{lc}
h_{g s}+l_{a n} & t=k T_{c} \\
h_{g s}+l_{a f} \sin q_{b}+l_{a n} \cos q_{b} & t=k T_{c}+T_{d} \\
H_{a o} & t=k T_{c}+T_{m} \\
\left(D_{s}-l_{a b}\right) \sin \lambda+l_{a b} \sin \left(q_{f}+\lambda\right)+l_{a n} \cos \left(q_{f}+\lambda\right) & t=(k+1) T_{c} \\
D_{s} \sin \lambda+l_{a n} \cos \lambda & t=(k+1) T_{c}+T_{d}
\end{array}\right.
$$

-Third phase:

$$
z_{a, \text { transient }}(t)=\left\{\begin{array}{lc}
h_{g s}+l_{a n} & t=k T_{c} \\
D_{s} \sin \lambda+l_{a n} \cos \lambda & t=k T_{c}+T_{d} \\
L_{a o} \sin \lambda+H_{a o} \cos \lambda & t=k T_{c}+T_{m} \\
\left(2 D_{s}-l_{a b}\right) \sin \lambda+l_{a b} \sin \left(q_{f}+\lambda\right)+l_{a n} \cos \left(q_{f}+\lambda\right) & t=(k+1) T_{c} \\
2 D_{s} \sin \lambda+l_{a n} \cos \lambda & t=(k+1) T_{c}+T_{d}
\end{array}\right.
$$

-Fourth phase: 


$$
z_{a, d e c}(t)=\left\{\begin{array}{lc}
D e c_{s t} D_{s} \sin \lambda+l_{a n} \cos \lambda & t=k T_{c} \\
\left(D e c_{s t} D_{s}+l_{a f}\right) \sin \lambda+l_{a f} \sin \left(q_{f}-\lambda\right)+l_{a n} \cos \left(q_{b}-\lambda\right) & t=k T_{c}+T_{d} \\
\left(D e c_{s t} D_{s}+L_{a o}\right) \sin \lambda+H_{a o} \cos \lambda & t=k T_{c}+T_{m} \\
\left((D e c s t+2) D_{s}-l_{a b}\right) \sin \lambda+l_{a b} \sin \left(q_{f}+\lambda\right)+\cdots & t=(k+1) T_{c} \\
l_{a n} \cos \left(q_{f}+\lambda\right) & \\
\left(D e c_{s t}+2\right) D_{s} \sin \lambda+l_{a n} \cos \lambda & t=(k+1) T_{c}+T_{d}
\end{array}\right.
$$

-Fifth phase:

$$
z_{a, \text { tran.2 }}(t)=\left\{\begin{array}{lc}
\left(D e c_{s t}+1\right) D_{s} \sin \lambda+l_{a n} \cos \lambda & t=k T_{c} \\
\left(\left(D e c_{s t}+1\right) D_{s}+l_{a f}\right) \sin \lambda+l_{a f} \sin \left(q_{b}-\lambda\right)+l_{a n} \cos \left(q_{b}-\lambda\right) & t=k T_{c}+T_{d} \\
\left(\left(k_{c h}-k_{c h 1}\right) D_{s}\right) \sin \lambda+H_{a o} & t=k T_{c}+T_{m} \\
\left(\left(k_{c h}-k_{c h 1}\right) D_{s}\right) \sin \lambda+l_{a b} \sin \left(q_{f}\right)+l_{a n} \cos \left(q_{f}\right) & t=(k+1) T_{c} \\
\left(\left(k_{c h}-k_{c h 1}\right) D_{s}\right) \sin \lambda+l_{a n} & t=(k+1) T_{c}+T_{d}
\end{array}\right.
$$

-Six phase:

$$
z_{a, \text { tran } .2}(t)= \begin{cases}\left(D e c_{s t}+2\right) D_{s} \sin \lambda+l_{a n} \cos \lambda & t=k T_{c} \\ \left(\left(D e c_{s t}+2\right) D_{s}+l_{a f}\right) \sin \lambda+l_{a f} \sin \left(q_{b}-\lambda\right)+l_{a n} \cos \left(q_{b}-\lambda\right) & t=k T_{c}+T_{d} \\ \left(\left(k_{c h 2}-k_{c h 1}\right) D_{s}\right) \sin \lambda+H_{a o} & t=k T_{c}+T_{m} \\ \left(\left(k_{c h}-k_{c h 1}\right) D_{s}\right) \sin \lambda+l_{a b} \sin \left(q_{f}\right)+l_{a n} \cos \left(q_{f}\right) & t=(k+1) T_{c} \\ \left(\left(k_{c h 2}-k_{c h 1}\right) D_{s}\right) \sin \lambda+l_{a n} & t=(k+1) T_{c}+T_{d}\end{cases}
$$

-Seven phase:

$$
z_{\text {a, level 2 ground }}(t)= \begin{cases}\left(\left(k_{c h 2}-k_{c h 1}\right) D_{s}\right) \sin \lambda+l_{a n} & t=k T_{c} \\ \left(\left(k_{c h 2}-k_{c h 1}\right) D_{s}\right) \sin \lambda+l_{a f} \sin \left(q_{b}\right)+l_{a n} \cos \left(q_{b}\right) & t=k T_{c}+T_{d} \\ \left(\left(k_{c h 2}-k_{c h 1}\right) D_{s}\right) \sin \lambda+H_{a o} & t=k T_{c}+T_{m} \\ \left(\left(k_{c h}-k_{c h 1}\right) D_{s}\right) \sin \lambda+l_{a b} \sin \left(q_{f}\right)+l_{a n} \cos \left(q_{f}\right) & t=(k+1) T_{c} \\ \left(\left(k_{c h 2}-k_{c h 1}\right) D_{s}\right) \sin \lambda+l_{a n} & t=(k+1) T_{c}+T_{d}\end{cases}
$$

-Eighth phase:

$$
z_{a, \text { stair,descending }}(t)= \begin{cases}\left(\left(k_{c h 2}-k_{c h 1}\right) D_{s}\right) \sin \lambda+l_{a n} & t=k T_{c} \\ \left(\left(k_{c h 2}-k_{c h 1}\right) D_{s}\right) \sin \lambda+l_{a f} \sin \left(q_{b}\right)+l_{a n} \cos \left(q_{b}\right) & t=k T_{c}+T_{d} \\ \left(\left(k_{c h 2}-k_{c h 1}\right) D_{s}\right) \sin \lambda+H_{a o} & t=k T_{c}+T_{m} \\ \left(\left(k_{c h}-k_{c h 1}\right) D_{s}\right) \sin \lambda+l_{a b} \sin \left(q_{f}\right)+l_{a n} \cos \left(q_{f}\right)+h_{s} & t=(k+1) T_{c} \\ \left(\left(k_{c h 2}-k_{c h 1}\right) D_{s}\right) \sin \lambda+l_{a n}+h_{s} & t=(k+1) T_{c}+T_{d}\end{cases}
$$

-Nine phase:

$$
z_{a, \text { stair, descending }}(t)= \begin{cases}\left(\left(k_{c h 2}-k_{c h 1}\right) D_{s}\right) \sin \lambda+l_{a n} & t=k T_{c} \\ \left(\left(k_{c h 2}-k_{c h 1}\right) D_{s}\right) \sin \lambda+l_{a f} \sin \left(q_{b}\right)+l_{a n} \cos \left(q_{b}\right) & t=k T_{c}+T_{d} \\ \left(\left(k_{c h 2}-k_{c h 1}\right) D_{s}\right) \sin \lambda+H_{a o} & t=k T_{c}+T_{m} \\ \left(\left(k_{c h}-k_{c h 1}\right) D_{s}\right) \sin \lambda+l_{a b} \sin \left(q_{f}\right)+\cdots & t=(k+1) T_{c} \\ l_{a n} \cos \left(q_{f}\right)+2 h_{s} & \\ \left(\left(k_{c h 2}-k_{c h 1}\right) D_{s}\right) \sin \lambda+l_{a n}+2 h_{s} & t=(k+1) T_{c}+T_{d}\end{cases}
$$


-Tenth phase:

$$
z_{a, \text { stair,descending }}(t)=\left\{\begin{array}{lc}
\left(\left(k_{c h 2}-k_{c h 1}\right) D_{s}\right) \sin \lambda+l_{a n}-S t_{c o n} h_{s} & t=k T_{c} \\
\left(\left(k_{c h 2}-k_{c h 1}\right) D_{s}\right) \sin \lambda+l_{a f} \sin \left(q_{b}\right)+\cdots & t=k T_{c}+T_{d} \\
l_{a n} \cos \left(q_{b}\right)+S t_{c o n} h_{s} & \\
\left(\left(k_{c h 2}-k_{c h 1}\right) D_{s}\right) \sin \lambda-\left(S t_{c o n}+1\right) h_{s}+H_{s} & t=k T_{c}+T_{m} \\
\left(\left(k_{c h 2}-k_{c h 1}\right) D_{s}\right) \sin \lambda+l_{a b} \sin \left(q_{f}\right)+\cdots & t=(k+1) T_{c} \\
l_{a n} \cos \left(q_{f}\right)+\left(S t_{c o n}+2\right) h_{s} & \\
\left(\left(k_{c h 2}-k_{c h 1}\right) D_{s}\right) \sin \lambda+l_{a n}-\left(S t_{c o n}+2\right) h_{s} & t=(k+1) T_{c}+T_{d}
\end{array}\right.
$$

In all the obtained relations, $l_{a b}, l_{a f}$ and $l_{a n}$ indicate the foot configuration as displayed in Fig. 4. $H_{s}, h_{s}$ and $S t_{c o n}$ indicate the stair height, foot's maximum height measured from the stair level and the step number of the robot over the stair. The trajectory path of the hip follows the above utilized procedure with respect to walking of the robot phases (Mousavi \& Bagheri, 2007). The applicable constraints of the ankle and hip joints have been discussed in (Mousavi \& Bagheri, 2007).

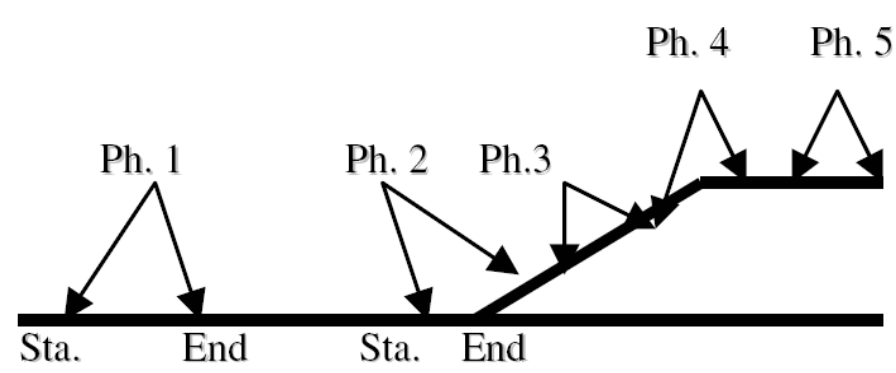

Fig. 3. The swing foot phases during gait.

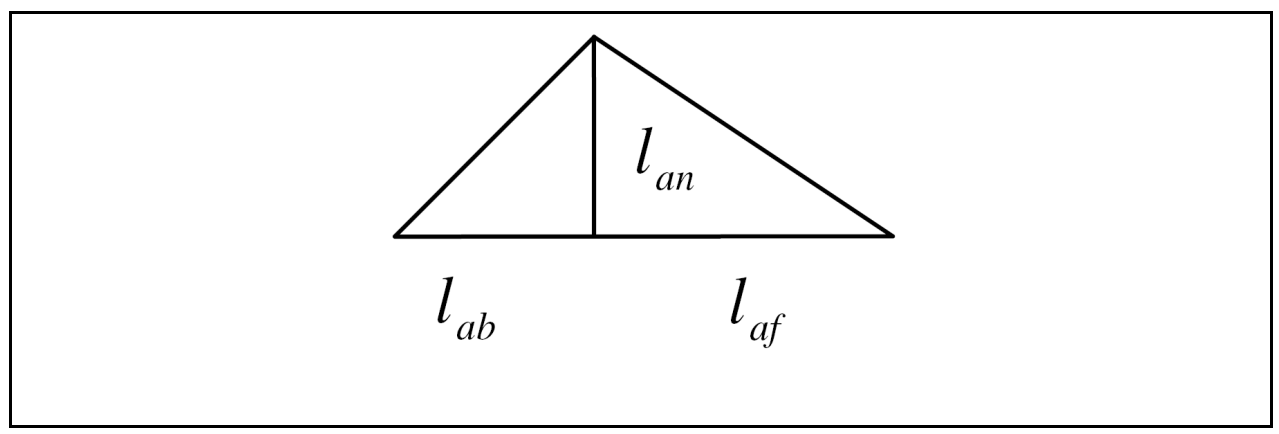

Fig. 4. The foot configuration. 


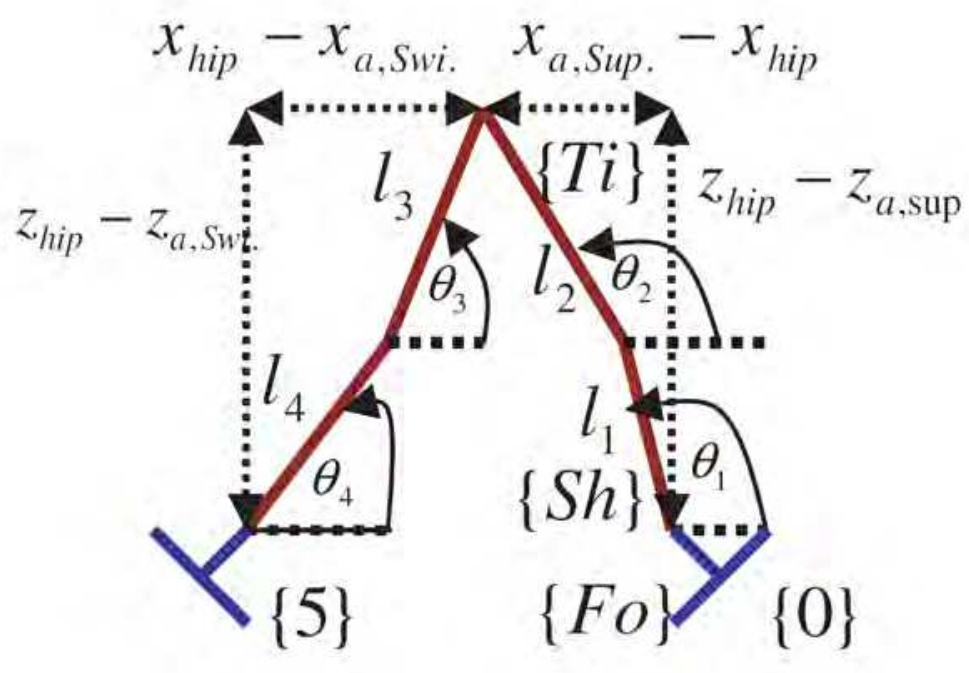

Fig. 5. The link's angles and configuration.

Now, the kinematic parameters will be obtained with respect to the above mentioned combined trajectory paths combined with the domain of the nonlinear equations (see Fig. 5). The nonlinear equations can be obtained as follows:

For support legs:

$$
\begin{aligned}
& l_{1} \cos \left(\pi-\theta_{1}\right)+l_{2} \cos \left(\pi-\theta_{2}\right)=a \\
& l_{1} \sin \left(\pi-\theta_{1}\right)+l_{2} \sin \left(\pi-\theta_{2}\right)=b
\end{aligned}
$$

For swing legs:

$$
\begin{aligned}
& l_{3} \cos \left(\theta_{3}\right)+l_{4} \cos \left(\theta_{4}\right)=c \\
& l_{3} \sin \left(\theta_{3}\right)+l_{4} \sin \left(\theta_{4}\right)=d
\end{aligned}
$$

where

$$
\begin{aligned}
& \mathrm{a}=\mathrm{x}_{\mathrm{a}, \text { sup }}-\mathrm{x}_{\text {hip }} \\
& \mathrm{b}=\mathrm{Z}_{\text {hip }}-\mathrm{Z}_{\mathrm{a} \text {,sup }} \\
& \mathrm{c}=\mathrm{X}_{\text {hip }}-\mathrm{X}_{\mathrm{a}, \text { swing }} \\
& \mathrm{d}=\mathrm{Z}_{\text {hip }}, \mathrm{Z}_{\mathrm{a} \text {, swing }}
\end{aligned}
$$

With the aid of the written programs and designed software, the above nonlinear equations based on the gait parameters are solved and also the link's angles are obtained. The kinematic parameters of the robot for single phase of the walking can be found in (Mousavi \& Bagheri, 2007; Mousavi, 2006). 


\section{Dynamic investigations}

With the biped's motion an important stability criteria (in similarities to the human gait) is defined using the zero moment point (ZMP). The ZMP is a point on the ground about which the sum of all the moments around is equal to zero. The ZMP formula is written as follows (Huang et al., 2001):

$$
x_{z m p}=\frac{\sum_{1}^{n} m_{i}\left(g \cos \lambda+\ddot{z}_{i}\right) x_{i}-\sum_{1}^{n} m_{i}\left(g \sin \lambda+\ddot{x}_{i}\right) z_{i}-\sum_{1}^{n}{ }_{i} I_{i} \ddot{\theta}_{i}}{\sum_{1}^{n} m_{i}\left(g \cos \lambda+\ddot{z}_{i}\right)}
$$

where $\ddot{x}_{i}, \ddot{z}_{i}$ are the vertical and horizontal acceleration of the mass center of link (i) with respect to the fixed coordinate system (which is on the support foot). $\ddot{\theta}_{i}$ is the angular acceleration of link (i) obtained from the interpolation process and $k$ denotes the slope of the surface. Principally, two types of ZMP are defined: (a) moving ZMP and (b) fixed ZMP.

The moving ZMP of the robot is similar to that for the human gait (Mousavi \& Bagheri, 2007). In the fixed type, the ZMP position is restricted through the support feet or the user's selected areas. Consequently, the significant torso's modified motion is required for stable walking of the robot. For the process here, the software has been designed to find the target angle of the torso for providing the fixed ZMP position automatically. In the designed software, $q_{\text {torso }}$ shows the deflection angle of the torso determined by the user or calculated by the auto detector module of the software. Note that in the auto detector, the torso's motion needed for obtaining the mentioned fixed ZMP will be extracted with respect to the desired ranges. The desired ranges include the defined support feet area by the users or is determined automatically by the designed software. Note that the most affecting parameters for obtaining the robot's stable walking are the hip's height and position. By varying the parameters with an iterative method for $x_{\mathrm{ed}}, \mathrm{x}_{\mathrm{sd}}$ (Huang et al., 2001) and choosing the optimum hip height, the robot control process with respect to the torso's modified angles and the mentioned parameters can be performed. To obtain the joint's actuator torques, Lagrange equations (John, 1989) have been used at the single support phase as follows:

$\tau_{i}=H(q) \ddot{q}+C(q, \dot{q}) \dot{q}+G\left(q_{i}\right)$,

where $\mathrm{i}=0,2, \ldots, 6$ and $H, C, G$ are mass inertia, coriolis and gravitational matrices of the system which can be written as follows:

$$
H(q)=\left[\begin{array}{lllllll}
h_{11} & h_{12} & h_{13} & h_{14} & h_{15} & h_{16} & h_{17} \\
h_{21} & h_{22} & h_{23} & h_{24} & h_{25} & h_{26} & h_{27} \\
h_{31} & h_{32} & h_{33} & h_{34} & h_{35} & h_{36} & h_{37} \\
h_{41} & h_{42} & h_{43} & h_{44} & h_{45} & h_{46} & h_{47} \\
h_{51} & h_{52} & h_{53} & h_{54} & h_{55} & h_{56} & h_{57} \\
h_{61} & h_{62} & h_{63} & h_{64} & h_{65} & h_{66} & h_{67}
\end{array}\right] \quad C(q, \dot{q})=\left[\begin{array}{lllllll}
c_{11} & c_{12} & c_{13} & c_{14} & c_{15} & c_{16} & c_{17} \\
c_{21} & c_{22} & c_{23} & c_{24} & c_{25} & c_{26} & c_{27} \\
c_{31} & c_{32} & c_{33} & c_{34} & c_{35} & c_{36} & c_{37} \\
c_{41} & c_{42} & c_{43} & c_{44} & c_{45} & c_{46} & c_{47} \\
c_{51} & c_{52} & c_{53} & c_{54} & c_{55} & c_{56} & c_{57} \\
c_{61} & c_{62} & c_{63} & c_{64} & c_{65} & c_{66} & c_{67}
\end{array}\right]
$$




$$
G(q)=\left[\begin{array}{c}
G_{1} \\
G_{2} \\
G_{3} \\
G_{4} \\
G_{5} \\
G_{T O R}
\end{array}\right]
$$

The most important point of the double support phase signifies the occurrence of the impact between the swing leg and the ground. Due to presence of the reaction force of the ground, Newton's equations must be employed for determination of the reaction force applied through the double support phase ((Huang et al., 2001; Lum et al., 1999; Eric, 2003). The method of (Huang et al., 2001) for simulation of the ground reaction force has been used for the inverse dynamics. Now, we have chosen an impeccable method involved slight deviations for dynamical analysis of the robot included the Lagrangian and Newtonian relations. The components of the matrices are complex and the detailed mathematical relations can be found in (Mousavi, 2006).

\begin{tabular}{llllll}
\hline$l_{S h}$ & $l_{T i}$ & $l_{T o}$ & $l_{a n}$ & $l_{a b}$ & $l_{a f}$ \\
\hline $0.3 \mathrm{~m}$ & $0.3 \mathrm{~m}$ & $0.3 \mathrm{~m}$ & $0.1 \mathrm{~m}$ & $0.1 \mathrm{~m}$ & $0.13 \mathrm{~m}$ \\
$m_{S h}$ & $m_{T h}$ & $m_{T o}$ & $m_{F o}$ & $D_{s}$ & $T_{c}$ \\
$5.7 \mathrm{~kg}$ & $10 \mathrm{~kg}$ & $43 \mathrm{~kg}$ & $3.3 \mathrm{~kg}$ & $0.5 \mathrm{~m}$ & $0.9 \mathrm{~s}$ \\
$T^{l}$ & $T_{m}$ & $H_{a o}$ & $L_{a o}$ & $x_{\text {ed }}$ & $x_{\text {sd }}$ \\
$0.18 \mathrm{~s}$ & $0.4 \mathrm{~s}$ & $0.16 \mathrm{~m}$ & $0.4 \mathrm{~m}$ & $0.23 \mathrm{~m}$ & $0.23 \mathrm{~m}$ \\
$g_{g s}$ & $g_{g f}$ & $H_{\min }$ & $H_{\max }$ & $h_{s}$ & $H_{s}$ \\
0 & 0 & $0.60 \mathrm{~m}$ & $0.62 \mathrm{~m}$ & $0.1 \mathrm{~m}$ & $0.15 \mathrm{~m}$ \\
$I_{\text {Shank }}$ & & $I_{\text {tight }}$ & & $I_{\text {torso }}$ & $I_{\text {foot }}$ \\
$0.02 \mathrm{kgm}^{2}$ & & $0.08 \mathrm{kgm}^{2}$ & & $1.4 \mathrm{kgm}^{2}$ & $0.01 \mathrm{kgm}^{2}$ \\
$k_{C h}$ & & $k_{C h 1}$ & & $k_{C h 2}$ & \\
2 & 5 & & 7 & \\
\hline
\end{tabular}

Table 1. The simulated robot specifications

The following conditions must be applied during the simulation process:

if $k \leq k_{c h 1}$ and $k=k_{c h 2}+1 \quad \lambda=0$

if $k>k_{c h 1}$ and $k<k_{c h 2}+1 \quad \lambda=$ The user defined value

$D_{e c}$ the number of robot's steps over the slope

$k_{C h} \quad$ the number of steps that the robot changes during the walking process from the ground to slope

$k_{C h 1} \quad$ the number of steps that the robot changes during the walking process from slope to the ground

$k_{C h 2}$ the number of steps that the robot changes during the walking process from the ground to stair

The ranges of the fixed ZMP are selected with respect to the descending and ascending surfaces respectively as follows:

$-0.05 m \leq X_{z m p} \leq 0.26$

$-0.1 m \leq X_{z m p} \leq 0.26$ 


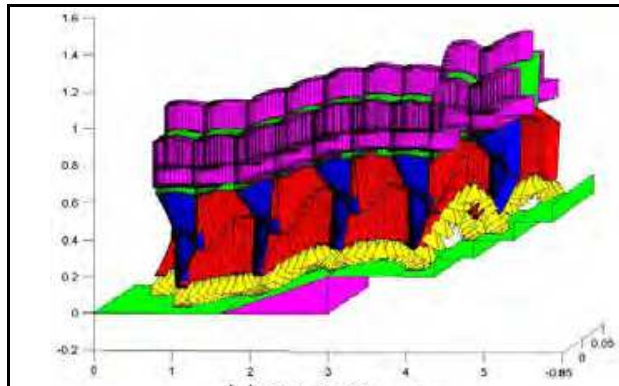

(a) Stick Diagram

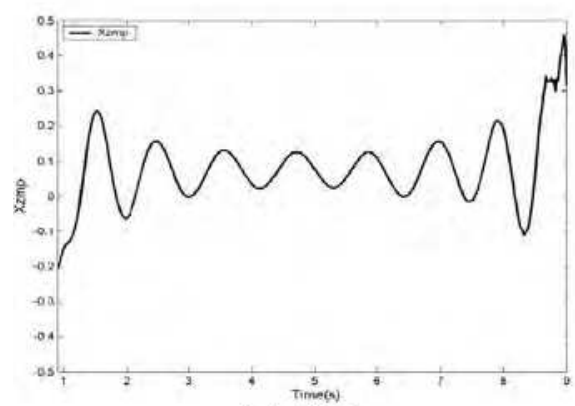

(c) ZMP

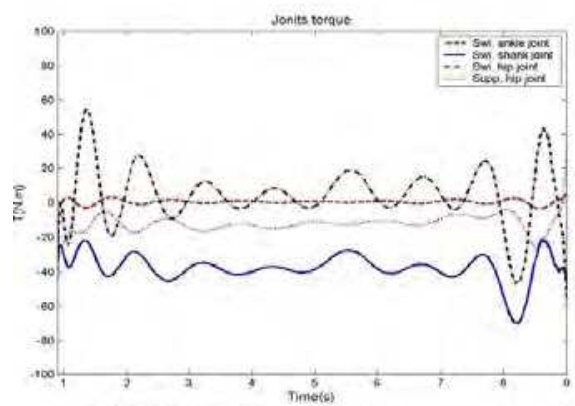

(e) The link's actuator torques

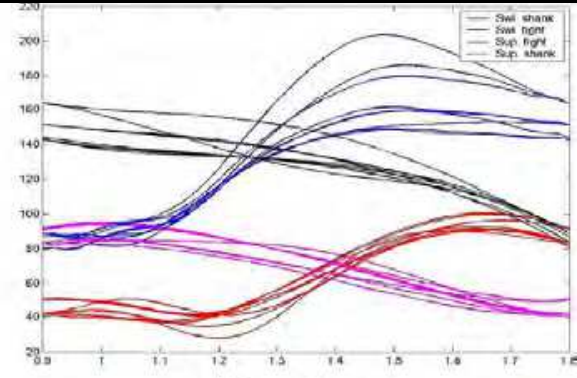

(b) Link's angles

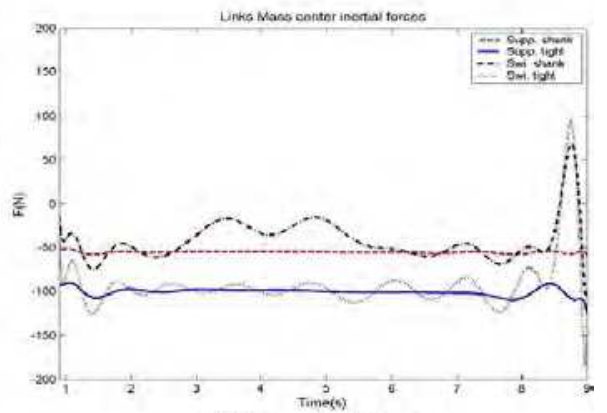

(d) Inertial Forces

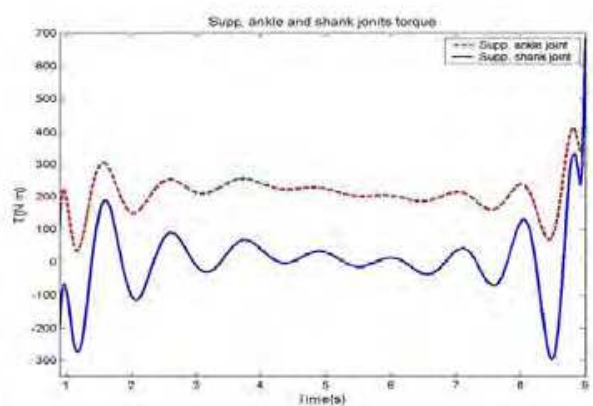

(f) The link's actuator torques

Fig. 6. (a) The robot's stick diagram on $\lambda=8^{\circ}$, moving ZMP, $H_{\min }=0.60 \mathrm{~m}, H_{\max }=0.62 \mathrm{~m}$; (b) the Link's angles during combined trajectory paths; (c) the moving ZMP diagram in nominal gait which satisfies stability criteria; (d) Inertial forces: (-) supp. thigh, (- - ) supp. shank, (...) swing thigh, (_. . .) swing shank; (e) joint's torques: (-) swing shank joint, (- - - ) swing ankle joint, (...) supp. hip joint, (....) swing hip joint; (f) joint's torques: (-) supp. Ankle joint, (- - ) supp. shank joint. 


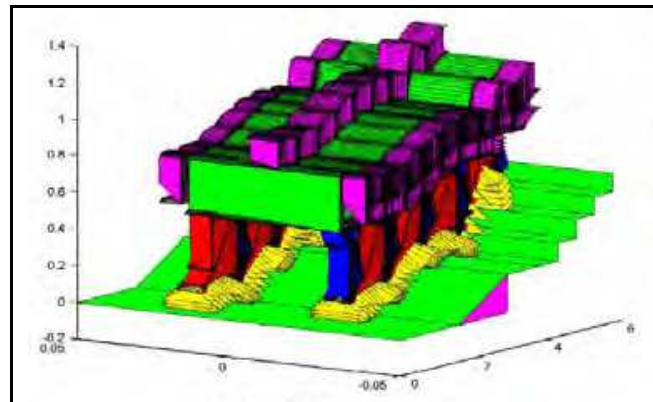

(a) Stick Diagram

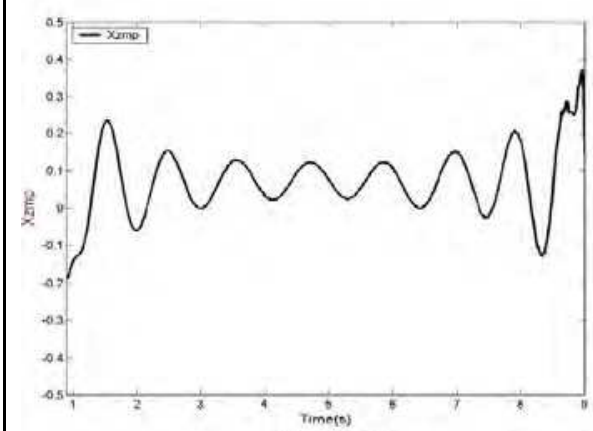

(c) ZMP

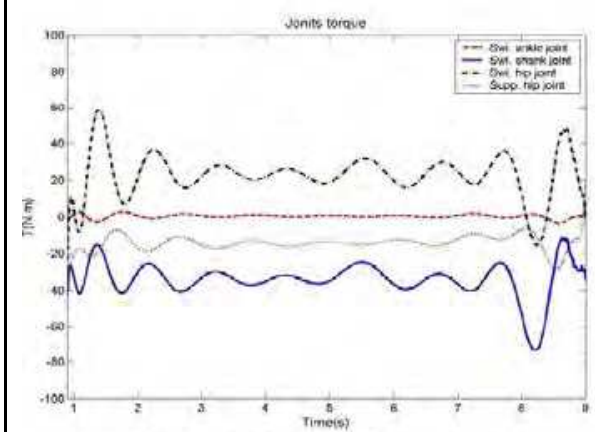

(e) The link's actuator torques

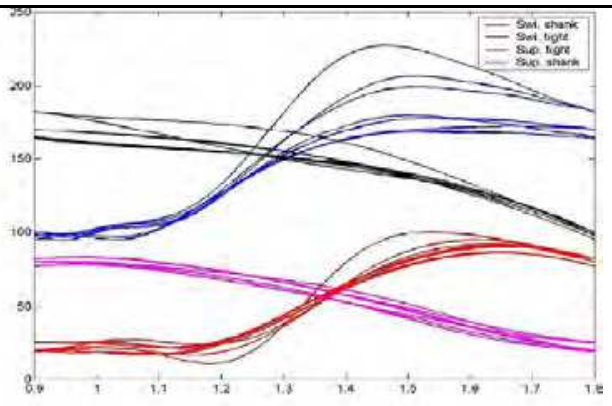

(b) Link's angles

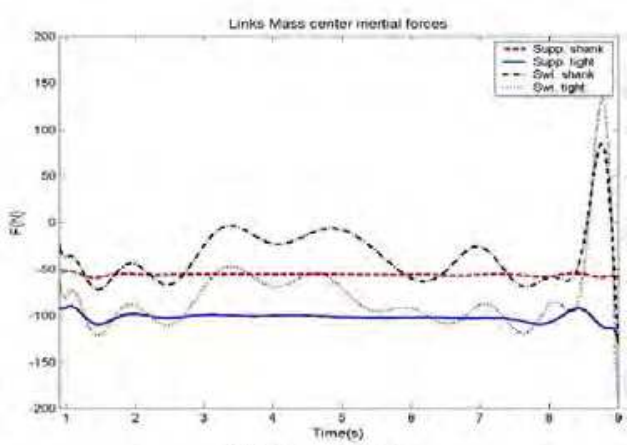

(d) Inertial Forces

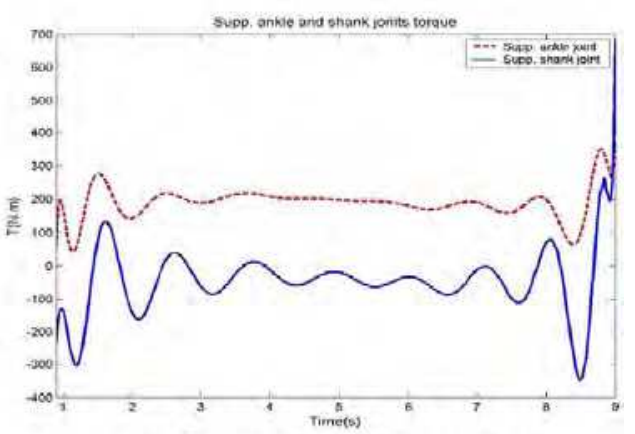

(f) The link's actuator torques

Fig. 7. (a) The robot's stick diagram on $\lambda=8^{\circ}$, moving ZMP, $H_{\min }=0.5 \mathrm{~m}, H_{\max }=0.52 \mathrm{~m}$. (b) The Link's angles during combined trajectory paths. (c) The moving ZMP diagram in nominal gait which satisfies stability criteria. (d) Inertial forces: (-) supp. thigh, (- - -) supp. shank, (...) swing thigh, (....) swing shank. (e) Joint's torques (-) swing shank joint, (- - -) swing ankle joint, (...) supp. hip joint, (....) swing hip joint. (f) Joint's torques: (-) supp. ankle joint, (- - -) supp. shank joint. 


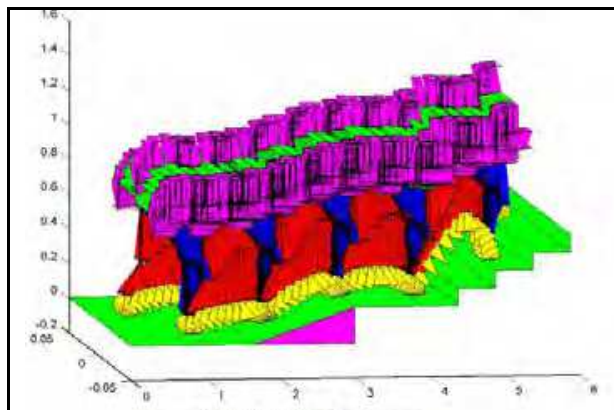

(a) Stick Diagram

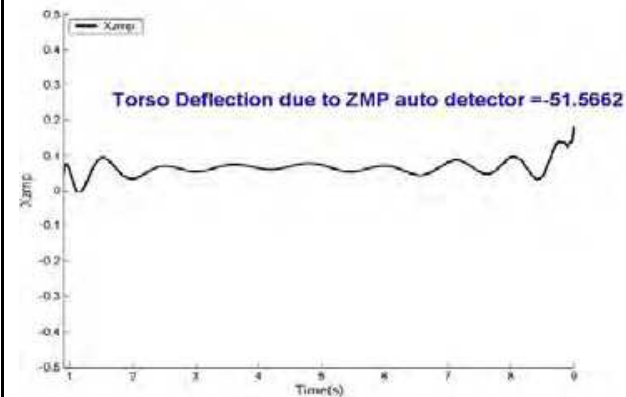

(c) ZMP

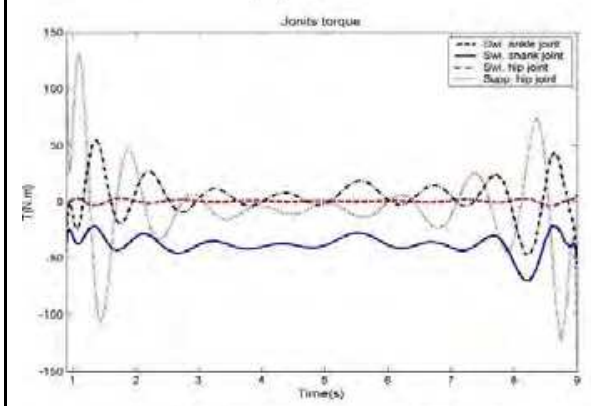

(e) The link's actuator torques

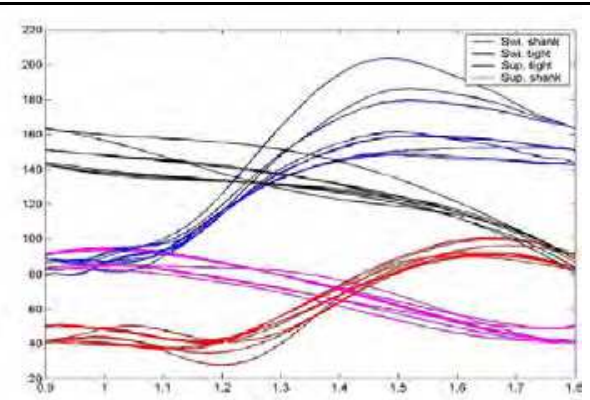

(b) Link's angles

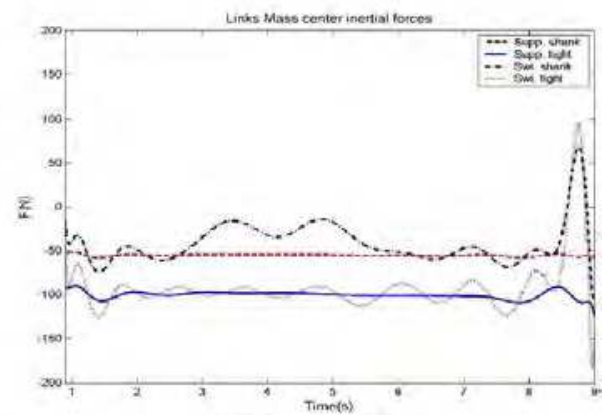

(d) Inertial Forces

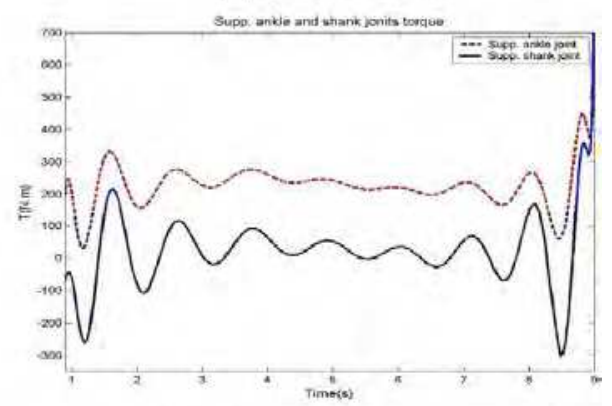

(f) The link's actuator torques

Fig. 8. (a) The robot's stick diagram on $\lambda=8^{\circ}$, fixed ZMP, $H_{\min }=0.6 \mathrm{~m}, H_{\max }=0.62 \mathrm{~m}$. (b) The Link's angles during combined trajectory paths. (c) The fixed ZMP diagram in nominal gait which satisfies stability criteria. (d) Inertial forces: (-) supp. thigh, (- - ) supp. shank, (...) swing thigh, (_. . .) swing shank. (e) Joint's torques (-) swing shank joint, (- - -) swing ankle joint, (...) supp. hip joint, (_...) swing hip joint. (f) Joint's torques: (-) supp. ankle joint, (- - ) supp. shank joint. 


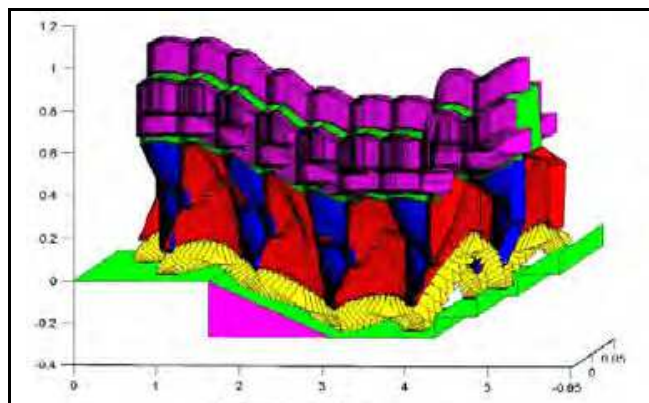

(a) Stick Diagram

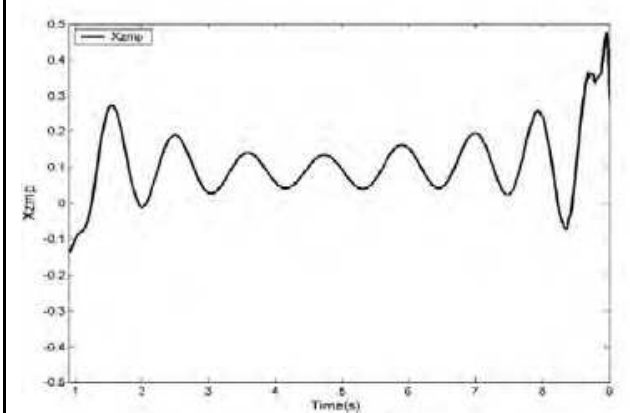

(c) ZMP

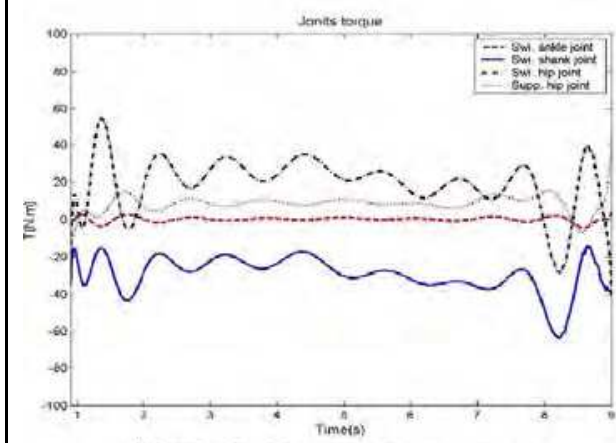

(e) The link's actuator torques

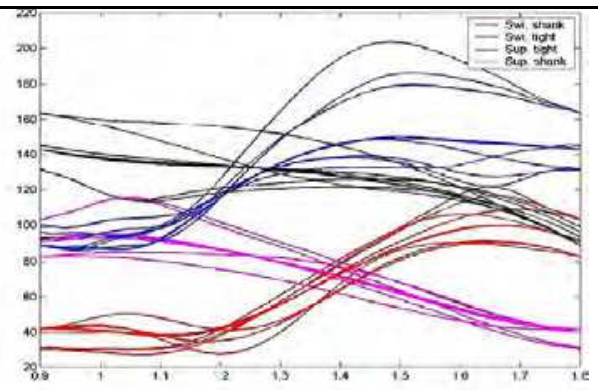

(b) Link's angles

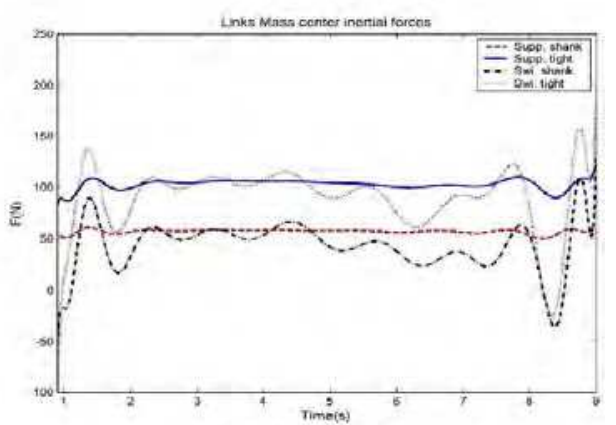

(d) Inertial Forces

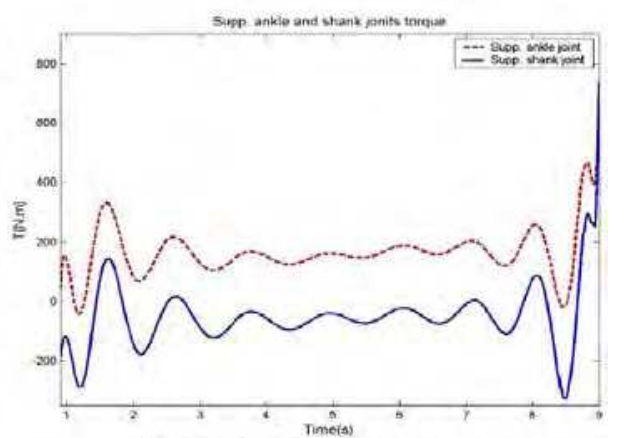

(f) The link's actuator torques

Fig. 9. (a) The robot's stick diagram on $\lambda=-10^{\circ}$, moving ZMP, $H_{\min }=0.6 \mathrm{~m}, H_{\max }=0.62 \mathrm{~m}$. (b) The Link's angles during combined trajectory paths. (c) The moving ZMP diagram in nominal gait which satisfies stability criteria. (d) Inertial forces: (-) supp. tight, (- - -) supp. shank, (...) swing thigh, (. . . ) swing shank. (e) Joint's torques: (-) swing shank joint, (- - -) swing ankle joint, (...) supp. hip joint, (....) swing hip joint. (f) Joint's torques: (-) supp. ankle joint, (- - ) supp. shank joint. 


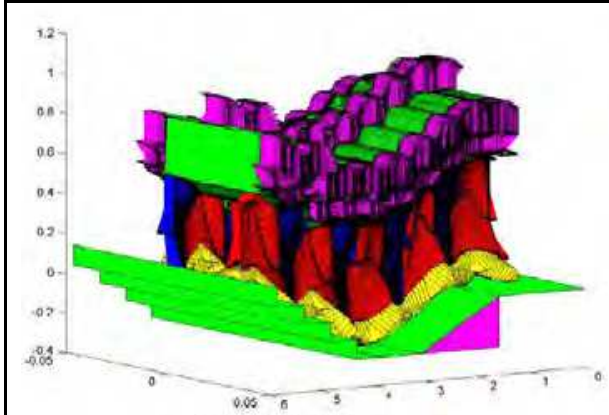

(a) Stick Diagram

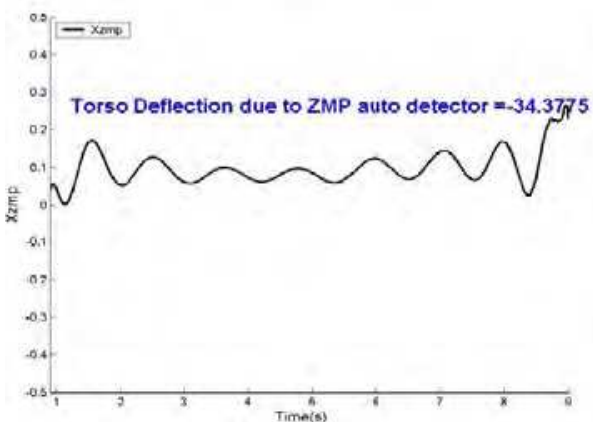

(c) ZMP

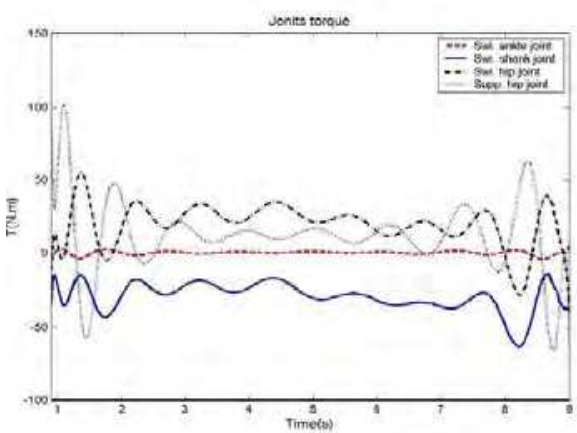

(e) The link's actuator torques

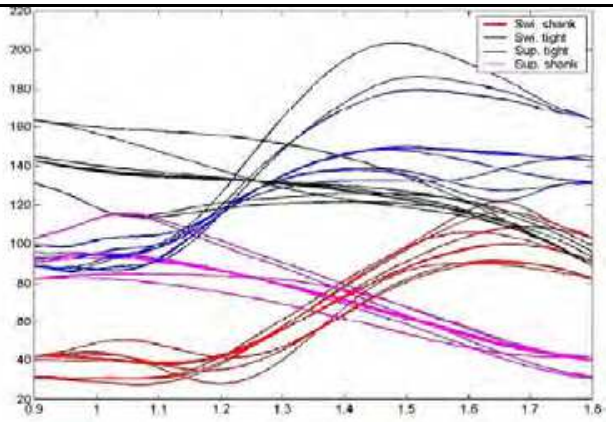

(b) Link's angles

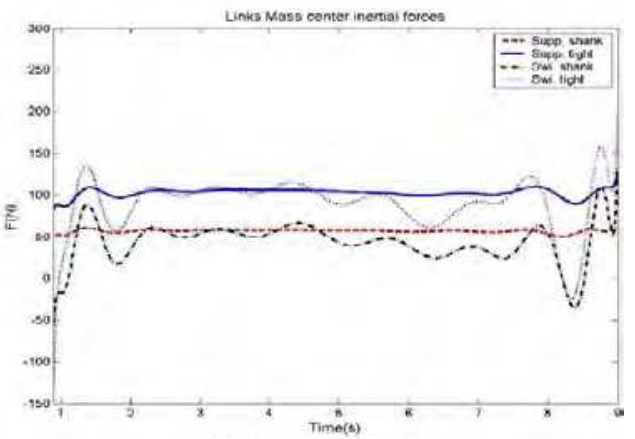

(d) Inertial Forces

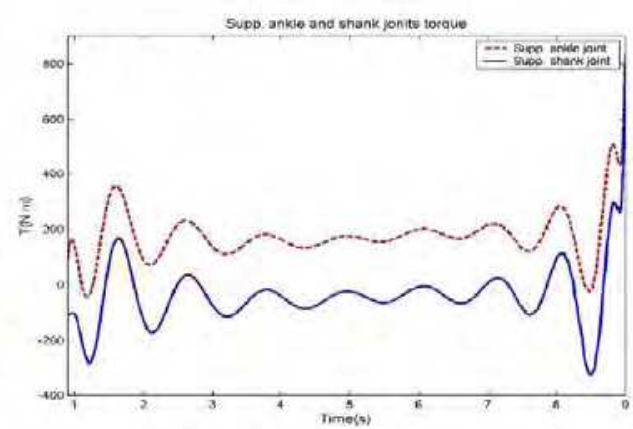

(f) The link's actuator torques

Fig. 10. (a) The robot's stick diagram on $\lambda=-10^{\circ}$, moving ZMP, $H_{\min }=0.6 \mathrm{~m}, H_{\max }=0.62 \mathrm{~m}$. (b) The Link's angles during combined trajectory paths. (c) The fixed ZMP diagram in nominal gait which satisfies stability criteria. (d) Inertial forces: (-) supp. thigh, (- - ) supp. shank, (...) swing thigh, (. . . ) swing shank. (e) Joint's torques: (-) swing shank joint, (- - -) swing ankle joint, (...) supp. hip joint, (. . . ) swing hip joint. (f) Joint's torques: (-) supp. ankle joint, (- - -) supp. shank joint. 


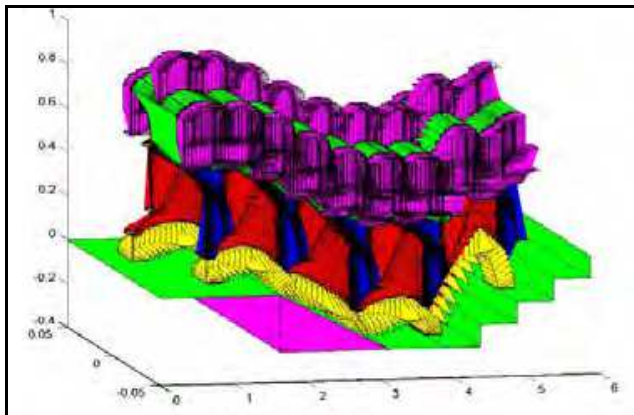

(a) Stick Diagram

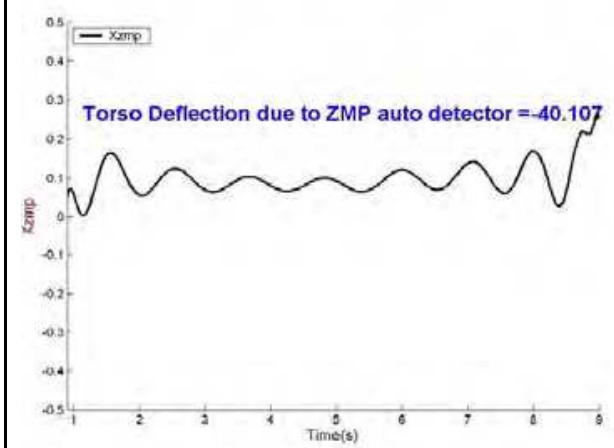

(c) ZMP

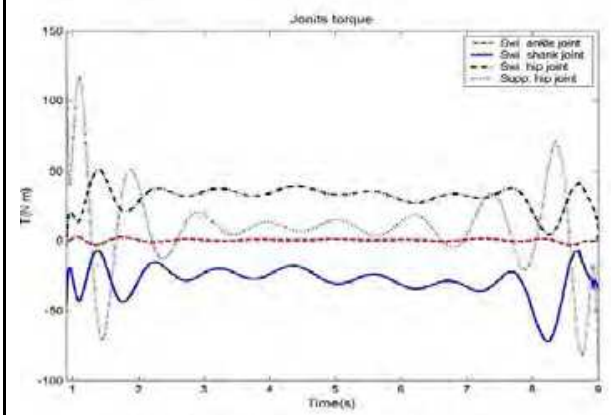

(e) The link's actuator torques

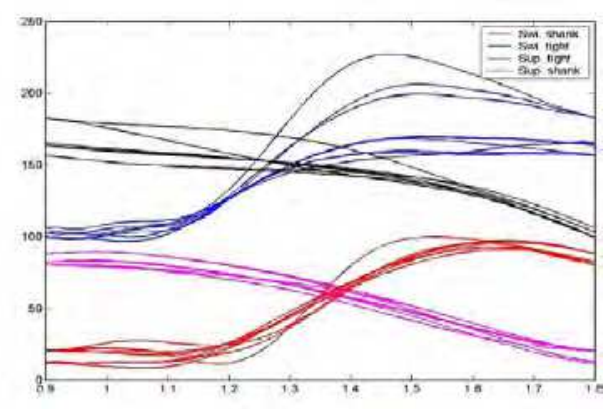

(b) Link's angles

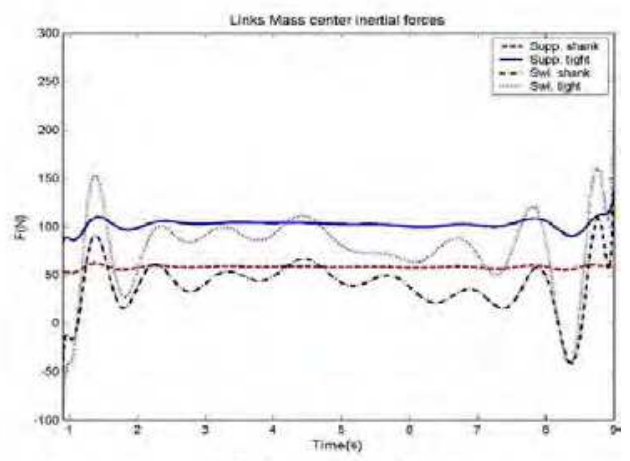

(d) Inertial Forces

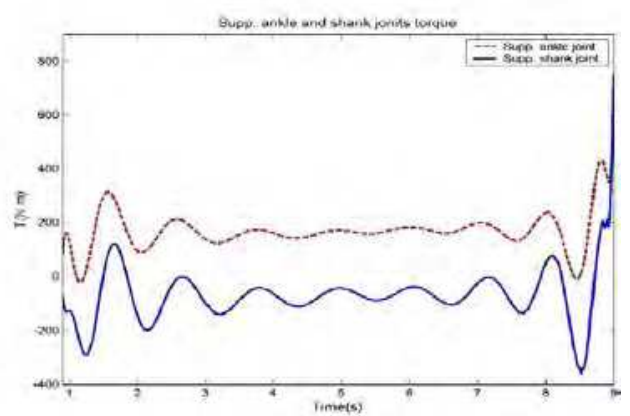

(f) The link's actuator torques

Fig. 11. (a) The robot's stick diagram on $\lambda=-10^{\circ}$, fixed ZMP, $H_{\min }=0.5 \mathrm{~m}, H_{\max }=0.52 \mathrm{~m}$. (b) The Link's angles during combined trajectory paths. (c) The fixed ZMP diagram in nominal gait which satisfies stability criteria. (d) Inertial forces: (-) supp. thigh, (- - -) supp. shank, (...) swing thigh, (_...) swing shank. (e) Joint's torques: (-) swing shank joint, (- - -) swing ankle joint, (...) supp. hip joint, (....) swing hip joint. (f) Joint's torques: (-) supp. ankle joint, (- - -) supp. shank joint. 
In the designed software, these methods are used to simulate the robot including AVI (audio and video interface) files for each identified condition by the users. Differentiating and also using the mathematical methods in the program, the angular velocities and accelerations of the robot's links are calculated to use in the ZMP, Lagrangian and Newtonian equations Table 1.

\section{Simulation results}

For the described process, the software has been designed based on the cited mathematical methods for simulation of a seven link biped robot. Because of the very high precision of third-order spline method, this method has been applied to calculate the trajectory paths of the robot. The result is 14,000 lines of program in the MATLAB/SIMULINK environment for simulation and stability analysis of the biped robot. By choosing the type of the ZMP in the Fixed and Moving modes, stability analysis of the robot can be judged easily. For the fixed type of ZMP, the torso's modified motion has been regarded to be identical with respect to various phases of the robot's motion. The results have been displayed in Figs. 611. Figs. 6-8 present the combined trajectory paths for nominal and non-nominal (with changed hip heights from nominal values) walking of the robot over ascending surfaces. Figs. 9-11 present the same types of walking process over descending surfaces. Both ZMPs have been displayed and their effects on the joint's actuator torques are presented. The impact of swing leg and the ground has been included in the designed software (Huang et al., 2001; Lum et al., 1999; Hon et al., 1978).

\section{Conclusion}

In this chapter, simulation of combined trajectory paths of a seven link biped robot over various surfaces has been presented. We have focused on generation of combined trajectory paths with the aid of mathematical interpolation. The inverse kinematic and dynamic methods have implemented for providing the robot combined trajectory paths in order to obtain a smooth motion of the robot. This procedure avoids the link's velocity discontinuities of the robot in order to mitigate the occurrence of impact effects and also helps to obtain a suitable control process. The sagittal movement of the robot has been investigated while 3D simulations of the robot are presented. From the presented simulations, one can observe important parameters of the robot with respect to stability treatment and optimum driver torques. The most important factor is the hip height measured from the fixed coordinate system. As can be seen from Fig. $7 f$, the support knee needs more actuator torque than the value of the non-nominal gait (with lower hip height measured from the fixed coordinate system). This point can be seen in Figs. 8f and 10f. This is due to the robot's need to bend its knee joint more at a lower hip position. The role of the hip height is considerable over the torso's modified motion for obtaining the desired fixed ZMP position. With respect to Figs. 10c and 11c, the robot with the lower hip height needs more modified motion of its torso to satisfy the defined ranges of ZMP by the users. The magnitude of the torso's modified motion has drastic effects upon the control process of the robot. Assuming control process of an inverse pendulum included a stagnant origin will present relatively sophisticated control process for substantial deflection angle of pendulum. Note that the torso motion in a biped (as an inverted pendulum) includes both the rotational 
and translational movements which will complicate the process of control. Consequently, the lower torso's modified motion is desirable which can be derived from the higher hip height. Therefore, the hip height plays an important role in both the stability and optimum actuator torques of the joints. Meanwhile, the higher hip height will avoid the link's velocity discontinuities.

\section{References}

Bagheri, A. \& Mousavi, P. N. (2007). Dynamic Simulation of Single and Combined Trajectory Path Generation and Control of A Seven Link Biped Robot, In: Humanoid Robots New Developments, Armando Carlos de Pina Filho, (Ed.), 89-120, Advanced Robotics Systems International and I-Tech, ISBN 978-3-902613-00-4, Vienna Austria.

Chevallereau, C.; Formal'sky,. A. \& Perrin, B. (1998). Low Energy Cost Reference Trajectories for a Biped Robot, in: Proc. IEEE Int. Conf. Robotics and Automation, 1998, pp. 1398-1404.

Dasgupta, A. \& Nakamura, Y. (1999). Making Feasible Walking Motion of Humanoid Robots from Human Motion Capture Data, in: Proc. IEEE Int. Conf. Robotics and Automation, pp. 1044-1049.

Hirai, K; Hirose, M.; Haikawa, Y. \& Takenaka, T. (1998). The Development of Honda Humanoid Robot, in: Proc. IEEE Int. Conf. Robotics and Automation, pp. 13211326.

Huang, Q.; Yokoi, K.; Kajita, S.; Kaneko, K.; Arai, H.; Koyachi, N. \& Tanie, K. (2001). Planning Walking Patterns For A Biped Robot, IEEE Trans. Robot. Automat. 17 (3).

Hon, H.; Kim, T. \& Park, T. (1978). Tolerance Analysis of a Spur Gear Train, in: Proc. Third DADS Korean User's Conf, pp. 61-81.

John, J. G. (1989) Introduction to Robotics: Mechanics and Control, Addison-Wesley.

Lum, H. K.; Zribi, M. \& Soh, Y. C. (1999). Planning and Contact of A Biped Robot, Int. J. Eng. Sci. 37 -1319-1349.

McGeer, T. (1990). Passive walking with knees, in: Proc. IEEE Int. Conf. Robotics and Automation, pp. 1640-1645.

Mousavi, P. N. (2006). Adaptive Control of 5 DOF Biped Robot Moving on a Declined Surface, M.S. Thesis, Guilan University.

Mousavi, P. N. \& Bagheri, A. (2007). Mathematical Simulation of A Seven Link Biped Robot on Various Surfaces and ZMP Considerations, Applied Mathematical Modelling, vol. 31/1, Elsevier, pp. 18-37.

Shih, C. L; Li, Y. Z.; Churng, S.; Lee, T. T. \& Cruver, W. A. (1990). Trajectory Synthesis And Physical Admissibility For A Biped Robot During The Single Support Phase, in: Proc. IEEE Int. Conf. Robotics and Automation, pp. 1646-1652.

Shih, C. (1997). Gait Synthesis For A Biped Robot, Robotica, 15, 599-607.

Shih, C. L. (1999). Ascending And Descending Stairs For A Biped Robot, IEEE Trans. Syst. Man. Cybern. A 29 (3) 255-268.

Silva, F.M. \& Machado, J. A. T. (1999). Energy Analysis during Biped Walking, in: Proc. IEEE Int. Conf. Robotics and Automation, pp. 59-64.

Takanishi, A.; Ishida, M.; Yamazaki, Y. \& Kato, I. (1985). The Realization of Dynamic Walking Robot WL-10RD, in: Proc. Int. Conf. Advanced Robotics, pp. 459-466. 
Westervelt, E. R. (2003). Toward A Coherent Framework for the Control of Plannar Biped Locomotion, A Dissertation Submitted in Partial Fulfilment of the Requirements for the Degree of Doctor of Philosophy, (Electrical Engineering Systems), the University of Michigan.

Zarrugh, M. Y. \& Radcliffe, C.W. (1979). Computer Generation of Human Gait Kinematics, J. Biomech. 12, 99-111.

Zheng, Y. F. \& Shen, J. (1990). Gait Synthesis for the SD-2 Biped Robot to Climb Sloping Surface, IEEE Trans. Robot. Automat. 6, 86-96. 


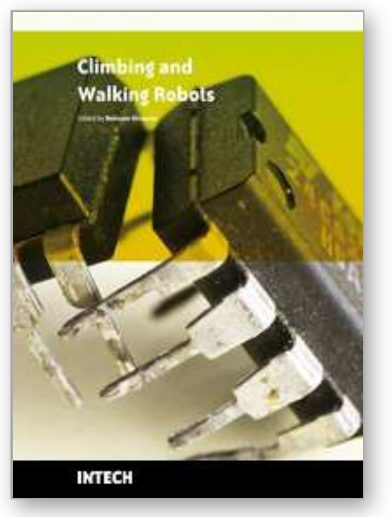

\author{
Climbing and Walking Robots \\ Edited by Behnam Miripour
}

ISBN 978-953-307-030-8

Hard cover, 508 pages

Publisher InTech

Published online 01, March, 2010

Published in print edition March, 2010

Nowadays robotics is one of the most dynamic fields of scientific researches. The shift of robotics researches from manufacturing to services applications is clear. During the last decades interest in studying climbing and walking robots has been increased. This increasing interest has been in many areas that most important ones of them are: mechanics, electronics, medical engineering, cybernetics, controls, and computers. Today's climbing and walking robots are a combination of manipulative, perceptive, communicative, and cognitive abilities and they are capable of performing many tasks in industrial and non- industrial environments.

Surveillance, planetary exploration, emergence rescue operations, reconnaissance, petrochemical applications, construction, entertainment, personal services, intervention in severe environments, transportation, medical and etc are some applications from a very diverse application fields of climbing and walking robots. By great progress in this area of robotics it is anticipated that next generation climbing and walking robots will enhance lives and will change the way the human works, thinks and makes decisions. This book presents the state of the art achievments, recent developments, applications and future challenges of climbing and walking robots. These are presented in 24 chapters by authors throughtot the world The book serves as a reference especially for the researchers who are interested in mobile robots. It also is useful for industrial engineers and graduate students in advanced study.

\title{
How to reference
}

In order to correctly reference this scholarly work, feel free to copy and paste the following:

Ahmad Bagheri, Behnam Miripour-Fard and Peiman Naseradin Mousavi (2010). Mathematical Modelling and Simulation of Combined Trajectory Paths of a Seven Link Biped Robot, Climbing and Walking Robots, Behnam Miripour (Ed.), ISBN: 978-953-307-030-8, InTech, Available from: http://www.intechopen.com/books/climbingand-walking-robots/mathematical-modelling-and-simulation-of-combined-trajectory-paths-of-a-seven-linkbiped-robot

\section{INTECH}

open science | open minds

\section{InTech Europe}

University Campus STeP Ri

Slavka Krautzeka 83/A

51000 Rijeka, Croatia

Phone: +385 (51) 770447

\section{InTech China}

Unit 405, Office Block, Hotel Equatorial Shanghai

No.65, Yan An Road (West), Shanghai, 200040, China

中国上海市延安西路65号上海国际贵都大饭店办公楼405单元

Phone: +86-21-62489820 
Fax: +385 (51) 686166

Fax: +86-21-62489821

www.intechopen.com 
(C) 2010 The Author(s). Licensee IntechOpen. This chapter is distributed under the terms of the Creative Commons Attribution-NonCommercialShareAlike-3.0 License, which permits use, distribution and reproduction for non-commercial purposes, provided the original is properly cited and derivative works building on this content are distributed under the same license. 